\title{
Violência simbólica no acesso das pessoas com deficiência às unidades básicas de saúde
}

Symbolical violence in the access of disabled persons to basic health units

Violencia simbolica en el acceso de las personas con discapacidad en las unidades básicas de salud

\author{
Inacia Sátiro Xavier de França', Lorita Marlena Freitag Pagliuca", \\ Rosilene Santos Baptista', Eurípedes Gil de França', Alexsandro Silva Coura', Jeová Alves de Souza' \\ 'Universidade Estadual da Paraíba. Departamento de Enfermagem. \\ Grupo de Estudos e Pesquisas em Atenção em Saúde Coletiva. Campina Grande, PB. \\ "Universidade Federal do Ceará. Departamento de Enfermagem. Fotaleza, CE
}

Submissão: 24/08/2009

Aprovação: 12/09/2010

RESUMO

Estudo descritivo que objetivou caracterizar condições de acesso das pessoas com deficiência (PCD) nas Unidades Básicas de SaúdeUBS. Coletaram-se dados em janeiro de 2009 em 20 UBSF. Utilizou-se máuuina digital e check list baseado na NBR 9050-ABNT. Os resultados apontaram: acesso urbano - ausência de semáforos (100\%), de faixas para pedestres (100\%), calçadas esburacadas (90\%). Acesso nas UBSF: portas fora do padrão legal (30\%) escadarias sem corrimão (20\%), piso fora do padrão (75\%); balcões em desacordo com padrão (20\%); local do bebedouro dificulta a utilização por cadeirante (30\%); não possui bebedouros ou filtros (15\%); telefones instalados inadequadamente (55\%); banheiros inacessíveis (96\%). Apesar da legislação específica, o acesso das PCD na maioria das UBSF é permeado pela violência simbólica.

Descritores: Enfermagem; Pessoas com deficiência; Acesso aos serviços de saúde; Estruturas de acesso.

\section{ABSTRACT}

A descriptive study which aimed to characterize the conditions of people with disabilities (PD) in the Basic Health Units-UBS. Data were collected in January 2009 in 20 UBSF. It was used digital camera and check list based on the 9050-NBR ABNT. The results showed: Access town - no traffic lights (100\%) of lanes for pedestrians (100\%), bumpy sidewalks (90\%); Access in UBS: non-standard ports (30\%) staircases without banisters (20\%); floor outside the standard (75\%), in disagreement with standard mobile (20\%), drinking at odds with standard (55\%), making it difficult to people with disabilities to use a filter (30\%), has no drinking or filters (15\%); telephones installed inadequately (55\%); inaccessible restrooms (96\%). Access to UBS of PD is permeated by the symbolic violence.

Key words: Nursing; Disabled persons; Health services accessibility; Architectural accessibility .

\section{RESUMEN}

Estudio descriptivo Que tuvo por objetivo caracterizar las condiciones de acceso de las personas com discapacidad (PCD) en las Unidades Basicas de Salud-UBS. La colecta de datos fue realizada en enero de 2009 en 20 UBSF. Se utilizó una máQuina digital y cheque-lista basada en la NBR 9050-ABNT y uma máeuina de fotografía. Los resultados han apuntado: acceso urbano - ausência de semáforos (100\%), de paso de peatones (100\%), aceras agujereadas (90\%). Acceso em las UBSF: puertas fuera del padrón legal (30\%), escaleras sin pasamano (20\%), suelo fuera del padrón (75\%), balcones em desacuerdo con padrón (20\%), local del bebedero dificulta la utilización por persona en silla de ruedas (30\%), no poseen bebederos or filtros (15\%), teléfonos com instalación inadecuada (55\%), cuartos de baño no son accesibles (96\%). No obstante legislación específica, el acceso de las PCD em la mayoría de las UBSF es marcado por la violência simbólico.

Descriptores: Enfermería; Personas con discapacidad; Accesibilidad a los servicios de salud; Estructuras de acceso.

\footnotetext{
AUTOR CORRESPONDENTE Inacia Sátiro Xavier de França. Rua Sérgio Rodrigues Oliveira, 139. CEP 58I03-074. Campina Grande, PB.

E-mail: isxf@oi.com.br
} 


\section{INTRODUÇÃO}

As políticas de saúde encampam uma polissemia de significados acerca das ações, saberes e práticas Que as constituem, fazendo desse paradigma um movimento em constante evolução. O conceito de saúde é articulado com outros conceitos, como o de ambiente, considerando-se as dimensões físicas, a exemplo de água, esgoto, resíduos sólidos domésticos e industriais, controle de vetores, dentre outros, e os fatores sociais, políticos, econômicos e culturais, para enfatizar a necessidade de ambientes saudáveis ${ }^{(1)}$.

A adoção de ambientes saudáveis requer intervenções com articulação intersetorial e participação social visando à consecução do direito à saúde e a melhoria das condições de vida da população ${ }^{(2)}$. Saúde e condições de vida remetem ao conceito acessibilidade Que é associado a acesso a areuitetura, comunicação, instrumentos, programas, atitudes, cultura ${ }^{(3)}$, dentre outros.

Em se tratando das Pessoas com Deficiência-PCD, o conceito acessibilidade define diretrizes discutidas e aprovadas em eventos nacionais e internacionais. No Brasil, o acesso dessas pessoas está regulamentado pelo Decreto 3.298/99(4), pela Lei $\mathrm{n}^{\circ}$ 10.098/ $2000^{(5)}$ e pela NBR 9050 da ABNT ${ }^{(6)}$. Essa última fixa as condições e os padrões de medidas exigíveis para propiciar as melhores e mais adeQuadas condições de acesso às vias públicas e ao mobiliário urbano.

Em solo brasileiro, existem 24.537.984 pessoas com algum tipo de deficiência física; 5.750 .809 com deficiência auditiva e 16.573.937 com deficiência visual. Na Paraíba, há 271.591 pessoas com algum tipo de deficiência física; 159.715 com deficiência auditiva e 473.222 com deficiência visual. E, no município paraibano em que esse estudo foi realizado, habitam, 30.000 pessoas com deficiência física e/ou sensorial ${ }^{(7)}$.

No Brasil, os estudos sobre acessibilidade das PCD são diminutos. Entretanto, demonstram a dificuldade de acesso desses indivíduos aos serviços de saúde devido às barreiras arquitetônicas e atitudinais ${ }^{(8)}$. Autores afirmam Que o comprometimento do acesso a bens e serviços de saúde expressam a não valorização da demanda espontânea de cuidados curativos ou preventivos, o Que contribui com a ocorrência de complicações no estado de saúde dessas pessoas ${ }^{(9)}$.

Pode-se inferir Que as barreiras atitudinais são representações dos julgamentos políticos, morais e estéticos Que compõem o habitus ${ }^{\left({ }^{(0)}\right)}$ de uma cultura dada. Como o habitus corresponde a uma matriz definida pela posição social do indivíduo, ele responde pelas condições de participação social baseando-se nos arquétipos do inconsciente coletivo. É no habitus Que se instaura a violência simbólica( ${ }^{(10)}$, um conceito Que corresponde a criação contínua de crenças e valores Que, socializados, se "naturalizam" no processo de dominação/exclusão dos indivíduos. Uma vez naturalizada, a violência simbólica induz os indivíduos a se posicionarem no espaço social orientando-se pelos critérios e padrões do discurso dominante. Logo, a violência simbólica se estabelece com o consentimento de Quem a sofre dado Que ela não é percebida como tal.

Em se tratando das PCD, as barreiras areuitetônicas e atitudinais são representações da violência simbólica instituída, em parte, pela naturalização da ação dos atores sociais e das instituições e, em parte, pelo desconhecimento do ordenamento jurídico Que ampara esses indivíduos. Daí porque é consenso Que, dentre os usuários do Sistema Único de Saúde (SUS), as PCD física e/ou visual são as Que enfrentam as maiores dificuldades de acesso, o Que sinaliza a necessidade de ampliação de estudos Que tragam avanços nessa área(III)

Esse estudo é relevante porQue é da competência das instituições de saúde zelar pelo acesso seguro dos seus usuários obedecendo a regras e normas destinadas a definir e regulamentar a prevenção e a segurança de todas as pessoas que ali convivem. A equipe de enfermagem colabora com esse processo respondendo pelas ações organizacionais e de administração de recursos para prestação de cuidados aos usuários ${ }^{(12)}$, e desenvolvendo ações preventivas de acidentes no ambiente de trabalho buscando, com engenheiros e arQuitetos da equipe de saúde, solução para escadarias sem corrimão, com altura ou largura dos degraus inadeQuadas, com pisos escorregadios ${ }^{(1)}$, dentre outros, em desacordo com as normas técnicas.

Entende-se que a acessibilidade institucional demonstra o zelo, dedicação, responsabilidade e envolvimento dos profissionais com o suprimento das necessidades humanas básicas das pessoas cuidadas $^{(13)}$. No caso específico do enfermeiro, assegurar o acesso da clientela demonstra, também, o cumprimento dos preceitos legais oriundos da Lei $\mathrm{N}^{0} 7.498 / 86^{(14)}$, no concernente ao artigo 11 Que, privativamente, Ihe delega a organização e direção dos serviços de enfermagem e de suas atividades técnicas e auxiliares; o planejamento, organização, coordenação, execução e avaliação dos serviços da assistência de enfermagem. E, como integrante da eQuipe de saúde, Ihe designa a participação em projetos de construção ou reforma de unidades de internação e a prevenção e controle sistemático de danos que possam ser causados à clientela durante a assistência de enfermagem.

Estudo realizado em instituições hospitalares públicas da Região Sul do Brasil ${ }^{(15)}$ Que são referências, em âmbito nacional e internacional, pelas suas experiências interdisciplinares na atenção à saúde, destaca Que o trabalho de suas equipes agrega, dentre outros, os fatores: vínculo, acolhimento, humanização da assistência e melhora no acesso dos usuários aos profissionais e aos serviços de saúde.

No caso desse estudo, o conhecimento da NBR 9050 da ABNT contribui com novas formas de organização do trabalho nas unidades básicas de saúde e com o desenvolvimento de competências, traduzidas em conhecimentos, habilidades e atitudes, Que possibilitem a atuação do enfermeiro na ęuipe multiprofissional, no enfrentamento dos desafios na formação de recursos humanos para a saúde, e na promoção da saúde por meio da participação no controle social do planejamento e execução das ações municipais de saúde.

Outrossim, na tomada de consciência do direito da PCD e da violência simbólica instalada, o enfermeiro e demais profissionais da saúde não podem esQuecer Que o desenho universal pode ter sido adotado no projeto arQuitetônico mas seu desconhecimento faz com Que seja desvirtuado no uso.

Ao considerar que o acesso aos ambientes e espaços físicos diz respeito à Qualidade de vida dos indivíduos ${ }^{(16)}$, Que existe legislação disciplinando as condições de acessibilidade, Que o município selecionado para a investigação tem elevado número de PCD, objetivou-se caracterizar as condições areuitetônicas de acesso das PCD física e/ou visual às Unidades Básicas de Saúde (UBS) de um 
município paraibano.

\section{MÉTODO}

Estudo descritivo realizado no período de novembro de 2008 a março de 2009 em 20 Unidades Básicas de Saúde-UBS da zona urbana de um município paraibano. O projeto foi aprovado por Comitê de Ética em Pesquisa sob o no 0490.0.133.000-08. Os pesquisadores obedeceram às diretrizes da Resolução 196/96 do Conselho Nacional de Saúde, garantindo o anonimato, a privacidade, e o sigilo da identidade dos atores envolvidos na peseuisa.

$\mathrm{O}$ instrumento foi um formulário check list, fundamentado na NBR 9050 da $\mathrm{ABNT}^{(6)}$ e uma máquina digital para fotografar as condições do acesso. Foram variáveis: acesso ao prédio, acesso ao interior do prédio, móveis e equipamentos, instalações sanitárias, bebedouros e telefones.

Priorizou-se o Desenho Universal, um conceito atrelado à idéia de sociedade inclusiva, considerando: Ambiente Acessível - se ajusta aos requerimentos funcionais e dimensionais, e possibilita a utilização autônoma, por todas as pessoas, com comodidade e segurança. Ambiente Praticável - não se ajusta a todos os requerimentos de acessibilidade, contudo, permite utilização autônoma por QualQuer pessoa. Ambiente Adaptável - reQuer modificações Que não afetam as configurações essenciais, para se tornar praticável. Ambiente Não-Acessível - não reúne os requisitos necessários para a acessibilidade $^{(16)}$.

Do agrupamento e categorização dos dados, emergiram os núcleos temáticos: 1) Ambiente Adaptável para PCD no tecido urbano; 2) Ambiente Não-Acessível para PCD no interior das UBS. Os resultados foram submetidos à estatística descritiva e apresentados em tabelas e figuras.

\section{RESULTADOS}

Os dados do estudo refletem as dificuldades de acesso das pessoas com deficiência física ou sensorial aos serviços de saúde. Para melhor clareza dos resultados, optou-se por apresentar as Tabelas 1 e 2 Que tratam, respectivamente, das condições de acesso no tecido urbano e no interior das UBS.

\section{Ambiente Adaptável para PCD no tecido urbano}

$\mathrm{Na}$ Tabela 1. são apontados os números e percentuais equivalentes às barreiras arQuitetônicas detectadas no percurso casa-
Unidade Básica de Saúde Que dificultam o acesso das PCD a essas instituições. Os piores resultados se referem a não disponibilidade de instrumentos de segurança no trânsito e de sinalização visual indicativa da localização da UBS.

Conforme apresentado na Figura 1 , determinados trechos do percurso às UBS é marcado por ausência de calçadas (Foto A); desnivelamentos na calçada (Foto B); presença de árvores e entulho nas ruas de acesso (Foto $\mathrm{C}$ ); e estacionamento de veículo frente à rampa de acesso dos usuários com dificuldade de locomoção (Foto D).

\section{Ambiente Não-Acessível para PCD no interior das UBS}

Os resultados apresentados na Tabela 2 sinalizam uma ambiência marcada pela violência simbólica no concernente ao direito de ire-vir, a segurança física das PCD, e ao atendimento de necessidades básicas para o funcionamento orgânico.

$\mathrm{Na}$ Figura 2, são apresentadas as principais barreiras ao acesso das PCD ao interior das UBS: escadaria (Foto E); porta de entrada principal (Foto F); áreas de circulação coletiva em desacordo com a norma técnica (Foto G); filtro localizado em balcão fechado (Figura H); e instalações sanitárias sem espaço livre junto às peças sanitárias e acessórios para transposição de pessoa usuária de cadeira de rodas (Foto I).

\section{DISCUSSÃO}

\section{Ambiente Adaptável para PCD no tecido urbano,}

Os percalços relativos à arQuitetura urbana detectados nesse estudo evidenciam a carga simbólico-afetiva Que coloca em risco a integridade física das pessoas Que utilizam esse espaço. Os dados da Tabela I demonstram que em 100\% das avenidas de acesso às UBS inexistem semáforos com botoeiras com caracteres do tipo Braille ou figuras em relevo; sinal sonoro Que emita sons com intensidade de, no mínimo, $15 \mathrm{~dB}$ acima do ruído de fundo. Apenas $10 \%$ das ruas têm placas com sinalização indicando o local da UBS; 10\% têm faixas de pedestres nas proximidades dessas instituições e 10\% têm rebaixamento de calçada em pontos estratégicos.

$\mathrm{Na}$ Figura I, apresentam-se as condições das calçadas para acesso às UBS: $90 \%$ estão esburacadas e $85 \%$ estão ocupadas por árvore, entulho ou lixeira. Nos locais de rebaixamento para acesso de pessoas com mobilidade física prejudicada às UBS, os veículos estacionam dificultando a mobilidade segura desses usuários.

Em relação à falta de sinalização nas ruas Que dão acesso às

Tabela 1. Demonstrativo de Ambiente Não-Acessível para PCD no tecido urbano de acesso às UBS. Brasil. 2009.

\begin{tabular}{|c|c|c|c|c|}
\hline \multirow{2}{*}{ Itens observados } & \multicolumn{2}{|c|}{ Presente } & \multicolumn{2}{|c|}{ Ausente } \\
\hline & $\mathrm{n}$ & $\%$ & $\mathrm{n}$ & $\%$ \\
\hline \multicolumn{5}{|l|}{ Acesso urbano } \\
\hline Semáforos com, ou sem, botoeiras de start para PCD física, & - & - & 20 & 100 \\
\hline Dispositivo sonoro específico para PCD visual. & - & - & 20 & 100 \\
\hline Ruas com sinalização indicando o local da UBS & 2 & 10 & 18 & 90 \\
\hline Ruas com rebaixamento de calçada em pontos estratégicos, & 2 & 10 & 18 & 90 \\
\hline Faixas para pedestres. & 2 & 10 & 18 & 90 \\
\hline Calçadas esburacadas, desniveladas. & 18 & 90 & 2 & 10 \\
\hline Calçadas com largura mínima de 1,5 m & 18 & 90 & 2 & 10 \\
\hline Árvore, entulho ou lixeira na calçada & 17 & 85 & 3 & 15 \\
\hline Estacionamento privativo para PCD & - & - & 20 & 100 \\
\hline
\end{tabular}


Tabela 2. Demonstrativo de Ambiente Não-Acessível para PCD no interior das UBS. Brasil. 2009.

\begin{tabular}{|c|c|c|c|c|}
\hline \multirow{2}{*}{ Itens observados } & \multicolumn{2}{|c|}{ Presente } & \multicolumn{2}{|c|}{ Ausente } \\
\hline & $\mathrm{n}$ & $\%$ & $\mathrm{n}$ & $\%$ \\
\hline \multicolumn{5}{|l|}{ Acesso ao prédio } \\
\hline Escadaria na entrada do prédio & 4 & 20 & 16 & 80 \\
\hline Rampas de acesso ao prédio & 12 & 60 & 8 & 40 \\
\hline $\begin{array}{l}\text { Acesso ao interior do prédio } \\
\text { Porta de entrada com largura inferior a } 80 \mathrm{~cm} \text {. }\end{array}$ & 6 & 30 & 14 & 70 \\
\hline Piso interno superfície regular, estável, firme e antiderrapante. & 5 & 25 & 15 & 75 \\
\hline Sinalização do acesso aos setores de assistência. & - & - & 20 & 100 \\
\hline Espaço reservado para pessoas em cadeiras de rodas & 11 & 55 & 9 & 45 \\
\hline \multicolumn{5}{|l|}{ Móveis e eQuipamentos } \\
\hline Balcões e mesas de trabalho têm altura de $80 \mathrm{~cm}$ do piso & 16 & 80 & 4 & 20 \\
\hline Bebedouros com os bicos a uma altura de $80 \mathrm{~cm}$ acima do piso & 9 & 45 & 11 & 55 \\
\hline Filtro de água em mobiliário Que dificulta a utilização por cadeirante. & 14 & 70 & 6 & 30 \\
\hline Não disponibiliza bebedouros ou filtros aos usuários & 3 & 15 & 17 & 85 \\
\hline Telefones instalados obedecendo a altura entre $80 \mathrm{~cm} \mathrm{e} 100 \mathrm{~cm}$ do piso. & 9 & 45 & 11 & 55 \\
\hline Disponibilidade de telefone público para os usuários. & 12 & 60 & 8 & 40 \\
\hline Recursos digitais, em Braille, para uso por PCD visual. & - & - & 20 & 100 \\
\hline \multicolumn{5}{|l|}{ Instalações sanitárias } \\
\hline Sanitários individualizados: feminino, masculino & 7 & 35 & 13 & 65 \\
\hline $\begin{array}{l}\text { Sanitário com espaço físico para manobras em linha reta e rotação de } 90 \text { e } 180 \text { graus no interior } \\
\text { dessas dependências. }\end{array}$ & 7 & 35 & 13 & 65 \\
\hline Porta do sanitário com largura igual ou maior Que $70 \mathrm{~cm}$ & 1 & 4 & 19 & 96 \\
\hline Sanitário com barras horizontais instaladas & 5 & 25 & 15 & 75 \\
\hline \multicolumn{5}{|l|}{ Área de aproximação da bacia sanitária e do lavatório } \\
\hline $\begin{array}{l}\text { Sanitário com dimensão do piso equivalente a um retângulo de } 1,10 \mathrm{~m} \text { por } 0,80 \mathrm{~m} \text { junto às peças } \\
\text { sanitárias }\end{array}$ & 6 & 30 & 14 & 70 \\
\hline Bacia sanitária instalada a uma altura de $46 \mathrm{~cm}$ do piso & 6 & 30 & 14 & 70 \\
\hline Papeleira instalada a uma a altura de $40 \mathrm{~cm}$ do piso & 8 & 40 & 12 & 60 \\
\hline Disponibilidade de papeleira & 5 & 75 & 15 & 25 \\
\hline Válvula de descarga a um $1,0 \mathrm{~m}$ do piso & 12 & 60 & 8 & 40 \\
\hline Torneiras do lavatório funcionam sob monocomando. & - & - & 20 & 100 \\
\hline Sanitário não possui toalheira ou saboneteira & 6 & 30 & 14 & 70 \\
\hline Espelho nas instalações sanitárias & - & - & 20 & 100 \\
\hline
\end{tabular}

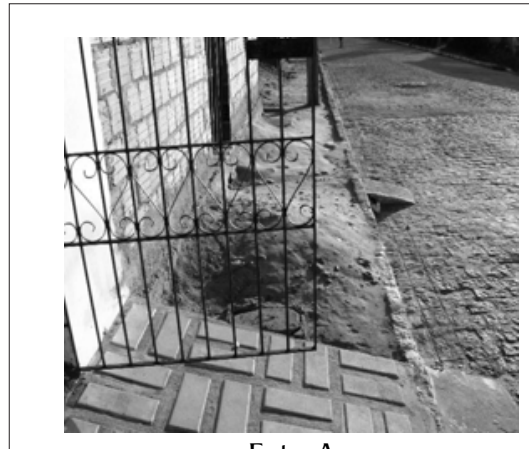

Foto A

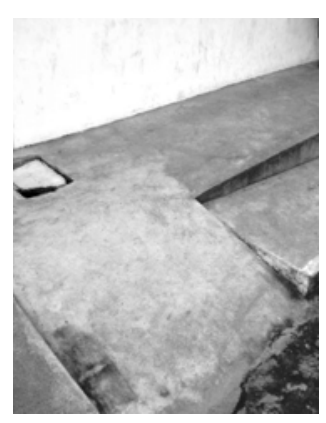

Foto B

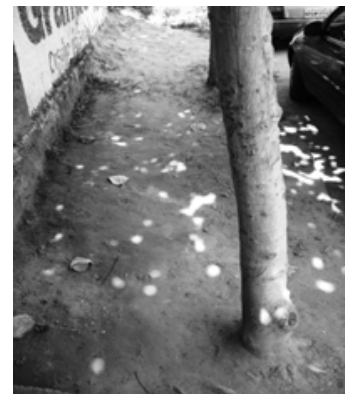

Foto C

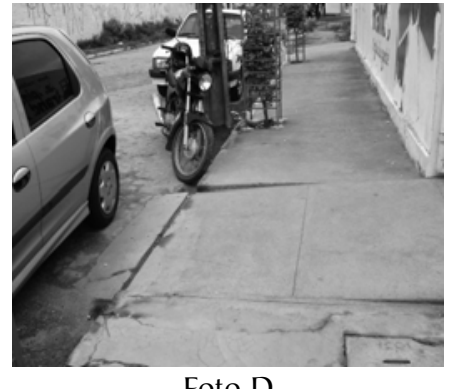

Foto D

Figura 1. Condições das calçadas para acesso às UBS. Brasil. 2009.

UBS, a NBR 9050 da ABNT recomenda o uso de placas de sinalização, e outros instrumentos Que tenham projeção sobre a faixa de circulação, colocados a uma altura de dois metros do piso. As informações visuais contidas nas placas devem ter textura, dimensionamento e contraste de cor dos textos e das figuras para Que sejam perceptíveis por pessoas com baixa visão ${ }^{(6)}$.

O Código de Trânsito Brasileiro determina Que as faixas de pedestres devem ser colocadas onde houver demanda de travessia, junto a semáforos, focos de pedestres, no prolongamento das calçadas e passeios. Um dos critérios para a colocação das faixas é Que em determinado espaço urbano haja circulação acima de 25 pedestres por minuto ${ }^{(6)}$.

O rebaixamento nas calçadas deve localizar-se nas esQuinas, nos meios de Quadra e nos canteiros divisores de pistas, independente desses locais terem, ou não, faixas ou semáforo. Não pode haver desnível entre o término do rebaixamento da calçada e 


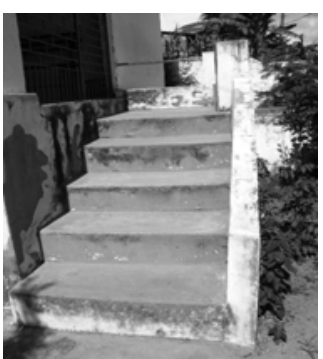

Foto $\mathrm{E}$

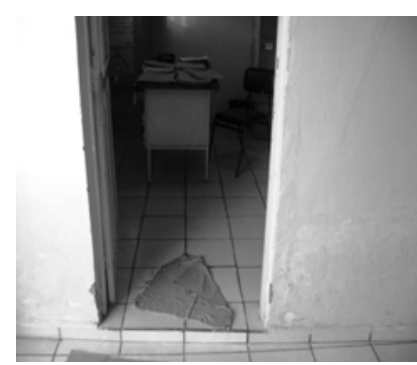

Foto $\mathrm{F}$

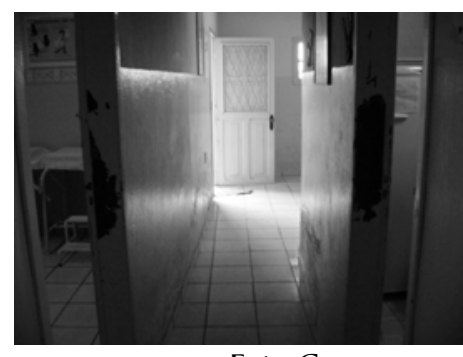

Foto G

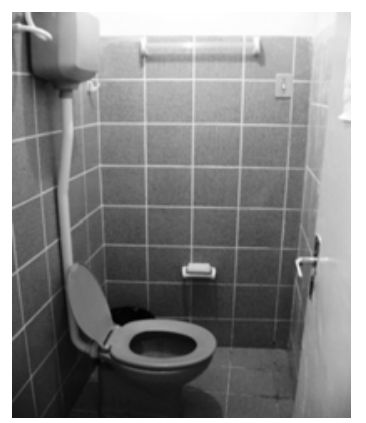

Foto I

Figura 2. Demonstrativo de Ambiente Não-Acessível para PCD no interior das UBS. Brasil. 2009.

o leito carroçável(6)

Para Que as PCD e as demais pessoas usufruam livre trânsito as calçadas precisam ter largura mínima de 1,50 metro para circulação de duas cadeiras de rodas. Havendo rebaixamento da guia, devese assegurar uma faixa livre no passeio, além do espaço ocupado pelo rebaixamento, de no mínimo $0,80 \mathrm{~m}^{(6)}$.

A presença de calçadas estreitas, com buracos, desnivelamento, árvores, entulho e lixeiras atentando contra o livre trânsito e a segurança dos transeuntes corrobora com outro relato em Que a locomoção de pessoas obesas, idosas e aquelas que fazem uso de cadeira de rodas, de muletas, de bengalas é dificultada devido as calçadas estarem ocupadas por comércios informais, motocicletas e bicicletas ${ }^{(17)}$.

No concernente ao fato de $100 \%$ das UBS não ter estacionamento privativo para PCD, a ABNT recomenda Que, nas vias públicas, para cada 100 vagas disponíveis para estacionamento uma deve ser para a $\mathrm{PCD}^{(6)}$.

O fenômeno "barreiras arquitetônicas" é fato comum no território brasileiro. Estudos realizados em outros estados ${ }^{(17-18)}$ apontam dificuldades do acesso das PCD no percurso casa-hospital condizentes com os mesmos achados desse estudo.

O difícil acesso das PCD nas áreas circunvizinhas às UBS, também, corrobora com o enunciado de outros autores segundo os Quais, a acessibilidade urbana costuma ser permeada por relações entre objetos Que muitas vezes possuem grande carga simbólicoafetiva com os usuários desse espaço, sendo capaz de incentivar, deprimir, cuidar ou mesmo pôr em risco o bem estar das pessoas Que utilizam esse espaço ${ }^{(19)}$.

A inacessibilidade das PCD na malha urbana sinaliza o conflito decorrente do confronto entre o capital cultural e o capital linguístico \% enquanto o Estado brasileiro cria e legitima um capital jurídico Que assegura o acesso das pessoas com deficiência a bens e serviços, o capital cultural se encarrega de naturalizar a violência simbólica ${ }^{(10)}$ por meio das divisões e hierarQuias sociais fundadas na diferença biológica.

Compreende-se que a acessibilidade não depende, apenas, da vontade e da ação do Estado. Apesar de já se observar melhorias no acesso ao tecido urbano do município investigado, ainda é preciso Que a sociedade entenda que cidade acessível é aquela Que promove a equiparação de oportunidade em todas as esferas da vida. Essa tomada de consciência implica co-responsabilidade dos cidadãos no planejamento e conservação da urbanização evitando a plantação de árvores nas calçadas, a colocação de entulhos e mobiliários nas vias públicas. E fiscalizando/solicitando aos setores responsáveis as adaptações necessárias para assegurar o acesso de todas as pessoas a bens e serviços, de modo Que as demandas sociais sejam ouvidas, valorizadas e atendidas pela administração pública, conforme estabelece a Lei $\mathrm{N}^{\circ} 10.257^{(20)}$ denominada Estatuto da Cidade.

Esse cuidado exige Que a ambiência atenda pressupostos do Desenho Universal, Que são da seguinte ordem: equiparação nas possibilidades de uso, flexibilidade no uso, uso simples e intuitivo, captação da informação, mínimo esforço físico e tolerância para o erro $^{(21)}$. Conforme esse pressuposto, o desenho acessível a todas as pessoas precisa do incremento de determinados dispositivos e adaptações do espaço urbano para viabilizar a maximização das competências e habilidades dos usuários, redução das dificuldades e barreiras encontradas de modo a lhes permitir participação, igualdade e mais independência para uma vida com Qualidade $^{(19)}$.

\section{Ambiente Não-Acessível para PCD no interior das UBS}

Os dados constantes na Tabela 2 sinalizam Que nem todas as pessoas podem exercitar, livremente, o direito de ir e vir, pois, 
apesar de todas as UBS terem estrutura térrea, em 20\% delas as PCD física ou visual não têm condição de adentrar porQue o acesso se dá por meio de escadas ou de rampas Que não obedecem às normas preconizadas pela NBR $9050^{(6)}$. As áreas de circulação coletiva de $65 \%$ dessas instituições têm largura inferior a 1,20 metros e possuem portas com largura inferior a 80 centímetros, medidas essas preconizadas pelas normas técnicas ${ }^{(6)}$

Em 100\% das UBS inexistem recursos digitais, em Braille, para uso por PCD visual. Em 75\% delas o piso não possui superfície regular, estável, firme e antiderrapante, pondo em risco a segurança física dos usuários. Esses achados corroboram com relato de outro estudo em Que as condições de acesso ao prédio, às áreas de circulação e ao mobiliário(II) se assemelham às agora apresentadas. Os autores desse outro estudo ${ }^{(1)}$ recomendam a sinalização visual para a indicação de percurso em edifício ou a distribuição dos seus ambientes por meio de setas associadas a textos, figuras ou símbolos. E para a indicação na forma tátil, utilização de recurso do tipo linha-guia ou piso tátil.

O mobiliário de $20 \%$ das UBS tem altura superior ao preconizado pelas normas técnicas ${ }^{(6)}$, segundo as Quais, os balcões de atendimento devem ser instalados a $0,80 \mathrm{~m}$ do piso, com altura livre mínima de $0,70 \mathrm{~m}^{(6)}$ permitindo aproximação frontal por cadeirante. A inobservância dessa especificação compromete o acesso do usuário cadeirante, determina uma sustentação postural inadequada Que pode desencadear perturbações de estima e comportamento.

Ainda, conforme a Tabela 2, 15\% das UBS não disponibilizam bebedouro ou filtro de água para os usuários. E em 30\% dessas instituições a disponibilização de filtros sobre mobiliário não permite aproximação lateral de uma pessoa cadeirante. Também, inexiste telefone público em 40\% das UBS, fato Que contraria a NBR 9050 Que recomenda Que se disponibilize um mínimo de $1 \%$ de telefones do tipo local e DDD, instalados de acordo com os requisitos de acessibilidade de modo a permitir sua utilização por $\operatorname{PCD}^{(6)}$.

As instalações sanitárias em $96 \%$ das UBS estão em desacordo com as normas técnicas, pois, a porta dos sanitários tem largura inferior a $70 \mathrm{~cm}^{(6)}$. Em $65 \%$ dessas dependências o espaço interno não possibilita as manobras necessárias para Que uma pessoa cadeirante possa utilizá-las. E em 75\% dessas instituições inexistem barras horizontais instaladas junto a bacia sanitária e ao lavatório para Que as pessoas com mobilidade prejudicada possam se apoiar ${ }^{(6)}$.

Investir na temática acesso da PCD na rede básica de saúde requer enfoque na ambiência, sem descuidar da arte e estética que permeiam uma atenção solidária, acolhedora, resolutiva e humana. ReQuer atenção ao capital jurídico estabelecido pela Constituição Federal de 1988, ao Decreto 3298/99(4) Que dispensa atenção a Saúde das pessoas com deficiência; a Lei № 10.098/2000(5) Que trata da acessibilidade; ao capital simbólico relacionado com a definição dos "sujeitos de direito"; e a própria dinâmica da assistência em saúde.

Em 2003, o Ministério da Saúde criou a Política Nacional de Humanização - HumanizaSUS, priorizando o atendimento com Qualidade e a participação integrada dos gestores, trabalhadores e usuários na consolidação do SUS. Dessa idéia emergiu a Cartilha do HumanizaSUS voltada para as Questões da ambiência Que sinaliza as diretrizes necessárias para se pensar os usuários do sistema de saúde como sujeitos moralmente merecedores de direitos $^{(22)}$

A Cartilha da PNH entende a ambiência hospitalar como um espaço social, profissional e de relações interpessoais, norteada pela inter-relação homem x espaço. Os seus pressupostos se apóiam em três objetivos: a) possibilitar a produção de sujeitos e o processo de trabalho; b) promover conforto a trabalhadores, paciente e sua rede social com enfoeue na privacidade e individualidade dos sujeitos envolvidos; e c) assegurar Que o espaço facilite o processo de trabalho funcional favorecendo a otimização de recursos e o atendimento humanizado, acolhedor e resolutivo ${ }^{(22)}$.

Para Que haja a produção do sujeito e do processo de trabalho é preciso Que haja o implemento de ações Que assegurem o acesso dos sujeitos e a integralidade nas ações em saúde. O princípio da integralidade defendido pelo SUS reconhece a saúde como um direito fundamental de todos os cidadãos cabendo ao Estado assegurar as condições indispensáveis ao usufruto desse direito promovendo o acesso aos serviços de saúde em todos os níveis de complexidade.

A idéia de integralidade preconizada pelo SUS gera a expectativa Que os gestores e profissionais de saúde reconheçam os usuários como sujeitos de fato, de direito, e com necessidades básicas que precisam ser atendidas. Entretanto, a inacessibilidade das PCD a algumas UBS compromete a proposição da integralidade como componente fundamental de cuidado em saúde e, consequentemente, compromete, também, a produção de sujeitos.

A análise das condições de acesso das PCD as UBS do município paraibano estudado demonstra Que, apesar desses indivíduos estarem, gradativamente, assumindo posições nos diversos espaços sociais, participando da vida em comum, essas conQuistas não tem garantido sensibilização e reflexão de todos os profissionais da saúde sobre as dificuldades encontradas por esses usuários no dia-a-dia, principalmente Quando as necessidades dessas pessoas dizem respeito à situação de doença. Na prática, a preocupação com a acessibilidade desses indivíduos aos ambientes hospitalares é diminuta, fato Que compromete a Qualidade da assistência prestada ${ }^{(10)}$.

Consoante esses resultados, pode-se afirmar Que a carga simbólico-afetiva Que promove a inacessibilidade das PCD aos bens e serviços é da ordem das barreiras atitudinais, focadas no desconhecimento das competências e necessidades das PCD.

\section{CONSIDERAÇÕES FINAIS}

O acesso das PCD física ou sensorial aos serviços de saúde engloba inúmeros fatores e pode ser analisado sob abordagens diversas. No caso desse estudo, ficou caracterizado Que a oferta de serviços não significa, necessariamente, atendimento efetivo da demanda, dado Que as dificuldades do acesso começam no tecido urbano, permeado pelas barreiras arquitetônicas e pela indisponibilidade de instrumentos sinalizadores do percurso casaUBS.

A dificuldade de acesso às UBS sinaliza o conflito entre o ordenamento jurídico Que assegura o acesso das PCD a Saúde, os pressupostos da NBR9050 Que estabelece parâmetros e padrões de acessibilidade arquitetônica, e as diretrizes emanadas da Cartilha da PNH Ambiência Que recomenda assistência visando a produção de sujeitos e o processo de trabalho, o respeito a privacidade e individualidade dos sujeitos envolvidos, e a funcionalidade do 
trabalho de modo a promover a otimização de recursos e o atendimento humanizado, acolhedor e resolutivo.

$\mathrm{O}$ acesso às UBS é permeado por condições em Que se percebe Que os gestores pensaram no atendimento às $\mathrm{PCD}$, mas as soluções apresentadas não atendem às reais necessidades desses usuários devido ao uso restrito das normas técnicas ${ }^{(6)}$. Dessa forma, o acesso dessas pessoas é permeado pela violência simbólica Que se caracteriza por tecido urbano carente de adaptação e ambiente não acessível no interior das UBS.

Espera-se Que os resultados desse estudo induzam a uma consciência crítica e reflexiva de modo a influenciar a minimização de obstáculos, ou otimizar o acesso das PCD física e/ou sensorial e propiciar uma nova abordagem do processo assistencial na busca da promoção da saúde e Qualidade de vida desse segmento social.

Por fim, é preciso que os gestores e as equipes de saúde adotem uma prática centrada em ações resolutivas das dificuldades de acesso dos usuários aos serviços, priorizando a assistência integral, universal, equitativa. Que essas ações sejam transformadoras das atitudes e comportamentos nas relações interpessoais e Que valorizem o controle social.

\section{REFERÊNCIAS}

I. Cohen SC, Bodstein R, Kligerman DC, Marcondes WB. Habitação saudável e ambientes favoráveis à saúde como estratégia de promoção da saúde. Ciênc Saúde Coletiva 2007; 12(1):191-98.

2. Pedrosa IIS. Perspectivas na avaliação em promoção da saúde: uma abordagem institucional. Ciênc Saúde Coletiva 2004; 9(3):617-26.

3. Fundação Banco do Brasil. Mídia e deficiência. Brasília; 2003. [citado em: 2009 Jan 23]. Disponível em: http:// www.andi.org.br/_pdfs/Midia_e_deficiencia.pdf

4. Brasil. Decreto $n^{\circ} 3.298$, de 20 de dezembro de 1999. Regulamenta a Lei $n^{\circ} 7.853$, de 24 de outubro de 1989, dispõe sobre a Política Nacional para a Integração da Pessoa Portadora de deficiência, consolida as normas de proteção, e dá outras providências. [citado em: 2009 jan 23]. Disponível em: https:/ /www.planalto.gov.br/

5. Brasil. Lei n. 10.098, de 19 de dezembro de 2000. Estabelece normas gerais e critérios básicos para promoção de acessibilidade das pessoas portadoras de deficiência ou com mobilidade reduzida e dá outras providências [online]. Brasília: 2000. [citado em: 2009 Jan 25]. Disponível em: http:// www.planalto.gov.br/ccivil/LEIS/L 10098.htm.

6. Associação Brasileira de Normas Técnicas. NBR 9050: Acessibilidade de pessoas portadoras de deficiências e edificações, espaço, mobiliário e equipamento urbano. Rio de Janeiro: ABNT; 1985.

7. Instituto Brasileiro de Geografia e Estatística. Censo demográfico do Brasil: 2000. Rio de Janeiro: IBGE; 2001.

8. Pagliuca LMF, Araújo TL, Aragão AEA. Pessoa com amputação e acesso ao serviço de saúde: cuidado de enfermagem fundamentado em Roy. Rev Enferm UERJ 2006; I 4(1): 100-6.

9. Souza IA, França ISXF. Prevalência de hipertensão arterial em pessoas com mobilidade física prejudicada. Rev Bras Enferm 2008; 61(6): 816-821.

10. Bourdieu P. O poder simbólico. $2^{\mathrm{a}}$ ed. Rio de Janeiro: Editora Bertrand Brasil; 1989.

11. Pagliuca LMF, Aragão AEA, Almeida PC. Acessibilidade e deficiência física: identificação de barreiras arQuitetônicas em áreas internas de hospitais de Sobral, Ceará. Rev Esc Enferm USP 2007; 4I (4):58I-88.

12. Passos NMG. O processo de acreditação: impacto nos serviços de enfermagem. Fortaleza: Pouchain; 2002.

13. Pianucci A. Saber cuidar: procedimentos básicos em enfermagem. $4^{\mathrm{a}}$ ed. São Paulo: SENAC; 2004.

14. Brasil. Lei 7.498, de 25 de junho de 1986. Dispõe sobre a Regulamentação do Exercício da Enfermagem e dá outras providências. Brasília: Ministério da Saúde; 1986. [citado em: 2010 jul 10]. Disponível em: http://www2.camara.gov.br/ internet/legislacao/legin.htm

15. Matos E, Pires DE, Campos GWS. Relações de trabalho em eQuipes interdisciplinares: contribuições para a constituição de novas formas de organização do trabalho em saúde. Rev Bras Enferm 2009; 62(6): 863-9.

16. Pupo DT, Melo AM, Ferres SP. Acessibilidade: discurso e prática no cotidiano das bibliotecas. Campinas: Unicamp/Biblioteca Central César Lattes; 2006.

17. Almeida PC, Aragão AEA, Pagliuca LMF, Macêdo KNF. Barreiras arQuitetônicas no percurso do deficiente físico aos hospitais de Sobral, Ceará. Rev Eletrôn Enferm 2006; 8(2):205-12.

18. Pagliuca LMF, França ISX, Moura ERF, Caetano IA et al. Acessibilidade da pessoa portadora de deficiência física e/ou sensorial aos serviços de saúde: estudo das condições físicas e de comunicação. In: Ceará Secretaria de Saúde do Estado, organizador. Pesquisa para o SUS no Estado do Ceará: coletânea de artigos do PPSUS-1. Fortaleza: Secretaria de Saúde do Estado do Ceará; 2007. p. 143-70.

19. Luz FLL, Flemming L, Chimenthl Bz. Núcleo de peseuisa "vida sem barreiras". In: $4^{\circ}$ Congresso Internacional de Pesquisa em Design. [citado em: 2009 lan 23]. Disponível em: http:// www.anpedesign.org.br/artigos/pdf

20. Brasil. Lei 10257 , de 10 de julho de 2001 . Estatuto da cidade. Regulamenta os arts. 182 e 183 da Constituição Federal estabelece diretrizes gerais da política urbana e dá outras providências. [citado em: 2009 Jan 22]. Disponível em: http:/ /www.soleis.com.br/LI0257.htm.

21. Acessibilidade Brasil. Recursos de acessibilidade. Desenho Universal. [on line]. [citado em: 2009 Jan 22]. Disponível em: http://www.acessobrasil.org.br/index.php?itemid $=42$.

22. Ministério da Saúde (BR). Secretaria-Executiva. Núcleo Técnico da Política Nacional de Humanização. HumanizaSuS: ambiência. Brasília: Ministério da Saúde; 2004. 